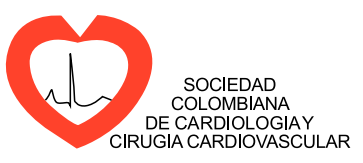

\title{
EDITORIAL
}

\section{Are we aware of a new atherosclerosis nomenclature? ${ }^{\text {is }}$ ¿Somos conscientes de una nueva nomenclatura de arterosclerosis?

\author{
Darío Echeverri ${ }^{\mathrm{a}, \mathrm{b}, \mathrm{c}}$
}

\author{
a Department of Hemodynamics and Cardiovascular Inverventionism, Fundación Cardioinfantil - Instituto de Cardiología, Bogotá, \\ Colombia \\ ${ }^{\mathrm{b}}$ Vascular Function Research Laboratory, Fundación Cardioinfantil - Instituto de Cardiología, Bogotá, Colombia \\ c Medical College, Universidad del Rosario, Bogotá, Colombia
}

Available online 1 July 2017

Coronary artery disease continues to be the main cause of morbidity and mortality worldwide, in spite of the many ongoing advances in the last years in prevention programs, and pharmacological and myocardial revascularization treatments. Although coronary artery disease patient survival has been improving, cardiovascular diseases represented 17.3 million deaths worldwide in 2012, and it is expected that this number will increase to more than 23.6 million in 2030. ${ }^{1}$ Recent estimates show that a third of the adult population in the United States (approximately 71.3 million) has some form of cardiovascular disease, including almost 17 million with coronary artery disease and 10 million with angina. ${ }^{2,3}$

The nomenclature of degenerative vascular diseases has been confusing and without unanimity of concepts. This reflects the lack of agreement among pathologists, as well as deficient classification proposals which do not unify the pathophysiological phenomena seen. In general, atheroma, derived from the Greek word athere, refers to a caseous material with high lipid content, in advanced intimal plaques. Atherosclerosis emphasizes the extensive sclerotic or fibrous tissue component of the lesion. In British literature, atheroma and atherosclerosis are frequently synonymous. Arteriosclerosis literally means

\footnotetext{
is Following the publication policy of this journal, this article, in which a member of the Scientific Committee has participated as coauthor, has gone trough a strict process of double-blind peer review and the authors did not interfere with the approval for publication.

E-mail address: decheverri@cardioinfantil.org
}

sclerosis, or hardening, of the arteries as a manifestation of age, regardless of the presence of atherosclerosis. In general, arteriosclerosis is a generic concept, and includes atherosclerosis, Mönckeberg arteriosclerosis and related age-induced changes in large and small peripheral arteries. Arteriolosclerosis refers to arteriolar wall thickening, fibrosis and hyalinization, with lumen narrowing. Phlebosclerosis literally means vein sclerosis or fibrosis.

Since the atherosclerosis classification described by Stary et al. ${ }^{4}$ more than 20 years ago (which was accepted by the scientific community and especially by the American Heart Association (AHA)), there have been important advances in diagnosis and pharmacological treatment, as well as percutaneous and surgical interventions. These have significantly influenced the disease, and have compelled a new nomenclature and new terms in clinical practice. In addition to native vessel atherosclerosis, which consists of the pathological process in a natural environment, two of the new pathologies are caused by the formation of an atheroma in an iatrogenic environment. One is saphenous vein graft atherosclerosis, and the other is neoatherosclerosis in segments previously treated with stents. Thus, two clearly different entities are conformed which we must address today (Table 1).

\section{Atherosclerosis in native coronary arteries}

At the end of the seventies, Ross highlighted the importance of smooth muscle cell proliferation in the formation of atherosclerotic lesions, and the hypothesis that the arterial 
wall lesion has a preponderant role in plaque progression. Later, inflammation was identified as the main driving force in smooth muscle cell activation and proliferation; processes which are mediated by growth factors. Subsequent studies at the end of the 90s indicated that the mechanism of disease progression involved a complex interaction between risk factors and inflammation. During this same period, Fuster et al. considered plaque progression as a phenomenon of staggered events and pinpointed that deep plaque fissures and ulcerations led to the manifestation of complex lesions, as a cause of luminal thrombosis and the clinical presentation of acute coronary syndrome.

In the 1990s, an AHA consensus document was published regarding atherosclerosis classification. ${ }^{4}$ This classification included six different categories:

- Type I, intimal thickening.

- Type II, fatty streaks.

- Type III, transitory or intermediate lesion.

- Type IV, advanced atheroma with a well-defined necrotic nucleus.

- Type V, fibroatheroma or atheroma with copious new superimposed fibrous connective tissue.

- Type VI, complicated plaques with superficial breaks (ruptures), hematoma or hemorrhage, thrombosis, or a combination of these characteristics.

However, this classification did not include two important clinical etiologies in the formation of acute coronary thrombi that differ from plaque rupture. These etiologies are superficial erosion, representing $25-30 \%$ of thrombosis cases, and eruptive calcified nodules which are less frequent, but still important, and are present in less than $5 \%$ of patients. In addition, in the mid-80s Davies had identified active lesions characterized by plaque fissures, as another means of communication between the lumen and the underlying necrotic nucleus, ${ }^{5}$ which was not included in the AHA classification.

With advances in biomarkers and intracoronary imaging of atherosclerotic plaque, the concept of vulnerable plaque as the precursor of rupture did not fit perfectly either, in an orderly, numerical classification. These restrictions, therefore, have led to the development of a modified framework, ${ }^{6}$ in which types I-IV of the lesions described in the AHA classification were replaced by the descriptive terms: adaptive intimal thickening, intimal xanthoma (fatty streaks), pathological intimal thickening, and fibroatheroma. Likewise, fibroatheromas have more recently been subcategorized as early and late phase plaques, based on the lytic and nonlytic characteristics of the necrotic nucleus. ${ }^{7}$ AHA categories $A$ and $V$ have been discarded because they did not take into account the three etiologies (rupture, erosion and calcified nodule) which lead to coronary thrombosis. Precursor lesions of plaque rupture, originally known as vulnerable plaques,

\section{Table 1 Atherosclerosis nomenclature.}

\begin{tabular}{ll}
\hline 1 & $\begin{array}{l}\text { Native vessel atherosclerosis } \\
\text { Includes arteriosclerosis and arteriolosclerosis I }\end{array}$ \\
2 & $\begin{array}{l}\text { Saphenous vein graft atherosclerosis } \\
3\end{array}$ \\
\hline
\end{tabular}

were classified as thin cap fibroatheromas (TCFA). Also, additional terms were introduced to signify arterial repair in the presence of plaques, with silent episodic thrombosis (healed plaque rupture) and plaque fissures.

\section{Atherosclerosis in saphenous vein grafts}

Coronary revascularization surgery is the standard of care for patients with multivessel disease, or left main trunk disease, and a diminished ejection fraction, as supported by many studies showing a reduction in morbidity and mortality related to percutaneous coronary intervention. Of the available graft options, internal mammary artery grafts have the best long-term permeability. However, only five to $10 \%$ of patients receive bilateral internal mammary arteries due to increased perioperative morbidity, mortality, length of surgery and risk of problems with the sternal wound. Moreover, $10-25 \%$ of saphenous vein grafts are occluded by thrombosis within one year of surgery, and an additional $1-2 \%$ are occluded each year from one to five years after surgery. In addition, 4-5\% are occluded each year in the six to ten years after surgery, due to accelerated atherosclerosis development. $^{8}$

Compared to native coronary arteries, saphenous vein grafts are more susceptible to atherosclerosis, and this pathology develops in an accelerated time frame. During the first year after implantation, all venous grafts show intimal thickening and an adaptive response to systemic circulation. Intimal hyperplasia consists of a concentric distribution of smooth muscle cells, proteoglycans and type III collagen. The earliest atherosclerotic change in saphenous vein grafts is reported at around one year, and is characterized by an accumulation of foam cells followed by the development of a necrotic nucleus, which is seen two to five years after surgery. Saphenous vein grafts which are more than five years old frequently show expansion of the necrotic nucleus through intraplaque hemorrhages. ${ }^{9}$ The hemorrhagic events could contribute to plaque rupture, and tend to occur between five and ten years after surgery. At 10 years, only $38-45 \%$ of saphenous vein grafts continue to be permeable. ${ }^{10}$

Histopathological analyses of saphenous vein grafts implanted for $8.5 \pm 5.9$ years have shown intimal thickening, a characteristic which contributes to a mean stenosis of $34 \pm 15 \% .{ }^{11}$ Lesions with exclusive foam cell infiltration (intimal xanthomas or «fatty streaks») were seen in $18.8 \%$ of the sections, with a percentage of stenosis of $37 \pm 9 \%$. Fibroatheromatous lesions with necrotic nuclei were observed in $11.9 \%$ of the sections, with a mean stenosis of $46 \pm 17 \%$. Intraplaque hemorrhage in a necrotic nucleus complications were evidenced in $7.5 \%$ of the sections. The less frequent plaque rupture and thrombosis lesion morphology was ascertained in $6.3 \%$ of the sections, with a mean stenosis of $75 \pm 24 \%$.

Circumferential intimal thickening is an early adaptive response in all saphenous vein grafts. Xanthomas, or fatty streaks, are typically present beyond one year. However, unlike native coronary disease, early saphenous vein graft lesions express variable degrees of macrophage apoptosis, entailing necrotic nuclei which cause plaque expansion. Lipid deposits are not involved in this process. Typical saphenous vein graft atherosclerosis is often concentric and 
diffuse, with a less well defined fibrous covering than in native coronary disease. The fibrotic capsule appears fragile and vulnerable to rupture.

The critical factors underlying rapid neointimal growth in saphenous vein grafts are the result of the endothelial lesion and excessive mechanical stretching of the vein under arterial pressure. Arterialization with fibrointimal thickening is a consistent adaptive change which occurs in less than one year old saphenous vein grafts. It is generally accompanied by a less than $50 \%$ narrowing of the cross-sectional area. A greater systolic and diastolic arterial pressure is considered to be a significant predictor of severe neointimal thickening and possible occlusion. Other factors include the diameter of the saphenous vein graft, right coronary artery graft, and the characteristics of the arterial beds in the operated vessels. ${ }^{12}$

The risk factors for cardiovascular disease also apply to saphenous vein graft disease. There is a good correlation between total cholesterol and the development of venous graft atherosclerosis. Aggressive treatment with statins which achieves LDL cholesterol level ranges of $93-97 \mathrm{mg} / \mathrm{dl}$, significantly reduces saphenous vein graft atherosclerosis (27\%). ${ }^{13}$ Statin or $\beta$-blocker treatment has also proven to be effective in limiting saphenous vein graft disease. ${ }^{12}$ In addition, antiplatelet treatment has been shown to reduce graft failure caused by thrombosis, but not long-term permeability. ${ }^{14}$

\section{Neoatherosclerosis}

Currently, percutaneous coronary intervention with stents (bare, or non-medicated stents, BMS) or drug-eluting stents (DES), is the most frequently performed procedure for treating patients with symptomatic coronary artery disease. Delayed arterial scarring and reparation with poor coverage of the stent struts is recognized as the primary substrate for stent thrombosis attributed to the DES. However, neoatherosclerosis within the stent segment has been reported as being another complication which presents both in first generation as well as second generation DES, resulting in late stent failure due to restenosis, or stent thrombosis caused by plaque rupture.

The introduction of coronary stents into the armamentarium of coronary artery disease treatment over two decades ago radically changed the coronary disease treatment regimen, worldwide. It is the most widely used procedure for managing patients with acute coronary syndrome and stable angina with severe coronary disease. Technological development has made better stent releasing systems available: metal alloy platforms (CoCr/PtCr, CoNi, PtLr, 316L) which make them more inert, with a lower possibility of peristrut inflammation and allergic reactions, while preserving their mechanical capabilities of flexibility and radial strength. These new metallic platforms have thinner strut designs, between 60 and $120 \mu \mathrm{m}$. There have also been important developments in stent-coating polymers (durable or biodegradable) in order to allow drug release (most of the Limus family: sirolimus, everolimus, zotarolimus, biolimus). The most recent studies show that the newer generation DES not only have advantages compared with the BMS, but also compared with first generation $\mathrm{DES}$, with regard to a significant long-term reduction in revascularization of the operated lesion (TLR; $5.0 \%$ vs. $8.6 \%)$, and definitive stent thrombosis ( $0.9 \%$ vs. $2.5 \%) .{ }^{15}$

Another important advance in cardiovascular interventionism technology is the bioresorbable non-metallic stents, or scaffolds (BVS). These are made of non-toxic bioabsorbable materials (poly-L-lactic acid - PLLA), which are completely reabsorbed within 2-3 years of implantation. They also release limus and offer a novel concept for the treatment of native atherosclerotic disease. Comparative studies of DES and BVS have shown similar results in TLR, but a greater incidence of definite and probable thrombosis. ${ }^{16}$ Therefore, among the stent limitations described today are: restenosis, thrombosis, and now, recently described, neoatherosclerosis.

The latter is defined as an accumulation of macrophages and foam cells within the neointima formed in a segment containing a stent, with or without the formation of a necrotic nucleus, calcification, or underlying thrombosis. ${ }^{17}$ This process implies that, beginning with neointimal formation (unlike native atherosclerosis), with a delayed reendothelialization process, and a reduction in smooth muscle cell activity with intercellular junction alterations, there is endothelial dysfunction, altered shear stress, pro-inflammatory phenotype cellular activation, an ongoing response to a foreign body, neovascularization, and macrophage recruitment. Histologically, it is characterized by macrophage deposition and the formation of live and apoptotic foam cells, the formation of a stable lipid nucleus, incipient microcalcifications within the intima, vulnerable plaques (TCFA), and intraplaque hemorrhages.

It is clear today, thanks to intravascular imaging and histopathological findings, that neoatherosclerosis in DES occurs faster and has more macrophages and foam cells, as well as the possibility of TCFA and the risk of plaque rupture, with possible stent thrombosis. ${ }^{18}$

Neoatherosclerosis is an entity whose clinical prevalence is still unknown. It can only be detected through intravascular imaging (intravascular ultrasound or optical coherence tomography - OCT). OCT has a greater axial resolution up to $10-20 \mu \mathrm{m}$, which allows the identification of foam cells in the intrastent neointima, and therefore early neoatherosclerosis. ${ }^{19}$ Based on imaging findings, there is a $21 \%$ prevalence of neoatherosclerosis in first generation DES with paclitaxel, $37 \%$ in those with sirolimus, and $29 \%$ in second generation everolimus-releasing DES. ${ }^{20}$

Currently, there is great interest in the neoatherosclerotic process as the cause of stent thrombosis, and its possible relationship with underlying native atherosclerosis. Neoatherosclerosis once again highlights the deficiencies in secondary prevention strategies.

In conclusion, the comprehension of the new atherosclerotic processes, and the morphological and pathophysiological comparisons of atherosclerotic plaque progression, should help advance understanding of native atherosclerotic disease, saphenous vein graft atherosclerosis, and neoatherosclerosis. This, in turn, should aid the development of improved strategies for modifying cardiovascular risk and secondary disease prevention. The near future is aimed at generating ideas and new strategies for identifying and treating atherosclerosis in all its forms, innovating anti-atherosclerotic treatment platforms, and strengthening secondary prevention programs. 


\section{References}

1. Laslett LJ, Alagona P Jr, Clark BA, Drozda JP Jr, Saldivar F, Wilson SR, et al. The worldwide environment of cardiovascular disease: prevalence, diagnosis, therapy, and policy issues: a report from the American College of Cardiology. J Am Coll Cardiol. 2012;60 Suppl.:S1-49.

2. Fihn SD, Gardin JM, Abrams J, Berra K, Blankenship JC, Dallas AP, et al., American College of Cardiology Foundation/American Heart Association Task Force. 2012. ACCF/AHA/ACP/AATS/PCNA/SCAI/STS guideline for the diagnosis and management of patients with stable ischemic heart disease: a report of the American College of Cardiology Foundation/American Heart Association task force on practice guidelines, and the American College of Physicians, American Association for Thoracic Surgery. Preventive Cardiovascular Nurses Association, Society for Cardiovascular Angiography and Interventions, and Society of Thoracic Surgeons. Circulation. 2012;126:e354-471.

3. Benjamin EJ, Blaha MJ, Chiuve SE, Cushman M, Das SR, Deo R, et al. Heart Disease and Stroke Statistics-2017 Update: A Report From the American Heart Association American Heart Association Statistics Committee and Stroke Statistics Subcommittee. Circulation. 2017;135:e146-603.

4. Stary HC, Chandler AB, Dinsmore RE, Fuster V, Glagov S, Insull $\mathrm{W} \mathrm{Jr}$, et al. A definition of advanced types of atherosclerotic lesions and a histological classification of atherosclerosis. A report from the Committee on Vascular Lesions of the Council on Arteriosclerosis, American Heart Association. Arterioscler Thromb Vasc Biol. 1995;15:1512-31.

5. Davies MJ, Thomas A. Thrombosis and acute coronary-artery lesions in sudden cardiac ischemic death. $N$ Engl J Med. 1984;310:1137-40.

6. Virmani R, Kolodgie FD, Burke AP, Farb A, Schwartz SM. Lessons from sudden coronary death: a comprehensive morphological classification scheme for atherosclerotic lesions. Arterioscler Thromb Vasc Biol. 2000;20:1262-75.

7. Kolodgie FD, Gold HK, Burke AP, Fowler DR, Kruth HS, Weber DK, et al. Intraplaque hemorrhage and progression of coronary atheroma. N Engl J Med. 2003;349:2316-25.

8. Bourassa MG, Fisher LD, Campeau L, Gillespie MJ, McConney M, Lespérance J. Long-term fate of bypass grafts: the Coronary Artery Surgery Study (CASS) and Montreal Heart Institute experiences. Circulation. 1985;72:V71-8.

9. Walts AE, Fishbein MC, Matloff JM. Thrombosed, ruptured atheromatous plaques in saphenous vein coronary artery bypass grafts: ten years' experience. Am Heart J. 1987;114:718-23.
10. Loop FD, Lytle BW, Cosgrove DM, Stewart RW, Goormastic M, Williams GW, et al. Influence of the internal-mammary- artery graft on 10-year survival and other cardiac events. N Engl J Med. 1986;314:1-6.

11. Yazdani SK, Farb A, Nakano M, Vorpahl M, Ladich E, Finn AV, et al. Pathology of drug-eluting versus bare-metal stents in saphenous vein bypass graft lesions. JACC Cardiovasc Interv. 2012;5:666-74.

12. Atkinson JB, Forman MB, Vaughn WK, Robinowitz M, McAllister $H A$, Virmani R. Morphologic changes in long-term saphenous vein bypass grafts. Chest. 1985;88:341-8.

13. Post Coronary Artery Bypass Graft Trial Investigators. The effect of aggressive lowering of low-density lipoprotein cholesterol levels and low-dose anticoagulation on obstructive changes in saphenous- vein coronary-artery bypass grafts. N Engl J Med. 1997;336:153-62.

14. Harskamp RE, Lopes RD, Baisden CE, de Winter RJ, Alexander $\mathrm{JH}$. Saphenous vein graft failure after coronary artery bypass surgery: pathophysiology, management, and future directions. Ann Surg. 2013;257:824-33.

15. Piccolo R, Pilgrim T, Heg D, Franzone A, Rat-Wirtzler J, Räber $L$, et al. Comparative effectiveness and safety of new generation versus early-generation drug-eluting stents according to complexity of coronary artery disease. J Am Coll Cardiol Int. 2015;8:1657-66.

16. Cassese S, Byrne RA, Ndrepepa G, Kufner S, Wiebe J, Repp J. Everolimus-eluting bioresorbable vascular scaffolds versus everolimus-eluting stents: a meta-analysis of randomized controlled trials. The Lancet. 2016;387:537-44.

17. Otsuka F, Byrne RA, Yahagi K, Mori H, Ladich E, Fowler DR, et al. Neoatherosclerosis: overview of histopathologic findings and implications for intravascular imaging assessment. Eur Heart J. 2015;36:2147-59.

18. Nakazawa G, Otsuka F, Nakano M, Vorpahl M, Yazdani SK, Ladich $\mathrm{E}$, et al. The pathology of neoatherosclerosis in human coronary implants bare-metal and drug-eluting stents. J Am Coll Cardiol. 2011;57:1314-22.

19. Malle C, Tada T, Steigerwald K, Ughi GJ, Schuster T, Nakano M, et al. Tissue characterization after drug-eluting stent implantation using optical coherence tomography. Arterioscler Thromb Vasc Biol. 2013;33:1376-83.

20. Otsuka F, Vorpahl M, Nakano M, Foerst J, Newell JB, Sakakura K, et al. Pathology of second generation everolimus-eluting stents versus first-generation sirolimus and paclitaxel-eluting stents in humans. Circulation. 2014;129:211-23. 